\title{
PENGARUH MODEL PEMBELAJARAN KOOPERATIF TIPE STUDENT TEAMS ACHIEVEMENT DIVISION (STAD) TERHADAP HASIL BELAJAR FISIKA SISWA KELAS X SMA NEGERI 2 MUARA BELITI TAHUN PELAJARAN 2015/2016
}

\author{
Ovilia Putri Utami Gumay, Eti Kodarsih dan Budi Mulyanto \\ Program Studi Pendidikan Fisika, Jurusan Pendidikan MIPA \\ Sekolah Tinggi Keguruan dan Ilmu Pendidikan PGRI Lubuklinggau \\ oviliateddy@yahoo.co.id
}

\begin{abstract}
ABSTRAK
Penelitian ini bertujuan untuk mengetahui pengaruh Model Pembelajaran Kooperatif tipe Student Teams Achievement Division (STAD) terhadap Hasil Belajar Fisika Siswa Kelas X SMA Negeri 2 Muara Beliti Tahun Pelajaran 2015/2016. Jenis penelitian ini adalah kuantitatif dengan metode penelitian eksperimen yang dilaksanakan dengan adanya kelompok pembanding desain pretest posttest control group design. Sebagai populasinya adalah seluruh siswa kelas X SMA Negeri 2 Muara Beliti tahun pelajaran 2015/2016, dengan teknik simple random sampling sampel penelitian adalah kelas X.3 kelas eksperimen dan siswa kelas X.8 sebagai kelas kontrol. Pengumpulan data dilakukan dengan teknik tes. Data yang terkumpul dianalisis dengan menggunakan uji-t. Berdasarkan hasil analisis uji-t pada taraf signifikan $\alpha=0,05$, diperoleh $t$ hitung $(7,83)>$ t tabel $(1,67)$ dengan data skor rata-rata pretest pada kelas Eksperimen 14,36 dan skor rata-rata postest 82,36. Dan skor rata-rata pretest pada kelas Kontrol 15,36 dan skor rata-rata postest 64,43. Sehingga dapat disimpulkan ada pengaruh yang signifikan model pembelajaran Kooperatif tipe Student Teams Achievement Division (STAD) terhadap hasil belajar fisika siswa kelas X SMA Negeri 2 Muara Beliti tahun pelajaran 2015/2016.

Kata kunci: Student Teams Achievement Division (STAD), Hasil belajar.
\end{abstract}

\section{ABSTRACT}

This thesis entitled "The Effect of Learning ModelCooperatif Tipe Student Teams Achievement Division $(S T A D)$ to the Physics Learning Outcomes Seventh Grade Students of SMA Negeri 2 Muara Beliti Academic Year 2015/2016". The purpose of this study was to determine the effect of learning model cooperatif tipe student teams achievement division $(S T A D)$ on learning outcomes physics class X student of SMA Negeri 2 Muara Beliti academic year 2015/2016. This research is a quantitative research method experiments carried out in the presence of a comparison group pretest posttest design group design. As the population is all students of class X SMA 2 Muara Beliti academic year 2015/2016, consisting of 216 and a sample is first class and the experimental class X.3 graders X.8 as the control class. The samples in this study were randomized (random sampling) by means of the draw. The data collection was done by using the test . The collected data were analyzed using t-test. Based on the results of t-test analysis at significance level $\mathrm{a}=0.05$, obtained $\mathrm{t}(7,83)>\mathrm{t}$ table (1.67). It can be concluded that there is significant influence learning model Cooperatif Tipe Student Teams Achievement Division (STAD) on learning outcomes physics class X student of SMA Negeri 2 Muara Beliti academic year 2015/2016.

Keywords : Make A Match, learning outcomes. 


\section{A. PENDAHULUAN}

Notoatmodjo (2003:16) mengemukakan bahwa pendidikan adalah segala upaya yang direncanakan untuk mempengaruhi orang lain baik individu, kelompok atau masyarakat sehingga mereka melakukan apa yang diharapkan oleh pelaku pendidikan. Pendidikan menurut Undang-Undang Republik Indonesia 20 Tahun 2003 tentang system Pendidikan Nasional (Sisdiknas) Bab 1 pasal 1 yaitu: Pendidikan adalah usaha sadar dan terencana untuk mewujudkan suasana belajar dan proses pembelajaran agar peserta didik secara aktif mengembangkan potensi dirinya untuk memiliki kekuatan spiritual keagamaan, pengendalian diri, kepribadian, kecerdasan, akhlak mulia, serta keterampilan yang diperlukan dirinya masyarakat, bangsa dan Negara. Berdasarkan penjelasan di atas, dapat disimpulkan bahwa pendidikan adalah usaha sadar dan terencana untuk mewujudkan suasana belajar agar peserta didik aktif mengembangkan dirinya untuk memiliki keterampilan yang diperlukan dirinya dan masyarakat secara umum. Jadi, disini pendidikan diharapkan dapat mengembangkan kemampuan yang dimiliki peserta didik, yaitu kemampuan berpikir dan kemampuan berprilaku. Peranan pendidikan dalam hal ini tidak hanya penting bagi perkembangan individu, melainkan perkembangan bangsa dan negara bahkan dunia. Melalui proses pendidikan diharapkan siswa dapat tumbuh dan berkembang menjadi lebih baik. Dalam pendidikan di sekolah, berhasil tidaknya pendidikan tidak hanya ditentukan oleh proses belajar mengajar yang telah dilakukan tetapi ditentukan juga oleh guru sebagai media dan fasilitator pembelajaran. Guru menjadi pemimpin belajar yang memberi fasilitas belajar dan lingkungan yang kondusif yang memungkinkan siswa untuk belajar dengan nyaman. Sukron (dalam Yulianto dan Rusmiyati, 2009:75), mengemukakan bahwa proses pembelajaran di sekolah menengah masih banyak menggunakan metode informatif. Proses pembelajaran yang biasa terjadi adalah siswa diarahkan kepada kemampuan untuk menghafal dan mengingat informasi. Siswa hanya menerima informasi yang disampaikan oleh guru dan jarang diikutsertakan dalam berpikir. Artinya, proses pembelajaran lebih banyak didominasi oleh guru. Berdasarkan hasil observasi awal peneliti dengan ibu Meli guru fisika di SMA Negeri 2 Muara Beliti, menunjukkan bahwa masih rendahnya hasil belajar siswa. Hal ini dibuktikan peneliti berdasarkan nilai ulangan harian materi besaran dan satuan siswa semester I tahun pelajaran 2015/2016. Nilai rata-rata siswa adalah 69,07, sedangkan kriteria ketuntasan minimum (KKM) yang terdapat disekolah tersebut adalah 75 . Kemudian persentase jumlah siswa yang tuntas sebesar $59,3 \%$ dan yang belum tuntas $40,7 \%$ dari 27 jumlah siswa. Putri, dkk (2013: 137) menyimpulkan bahwa "kurikulum yang digunakan dalam pendidikan nasional saat ini adalah kurikulum tingkat satuan pendidikan (KTSP) yang memerlukan strategi dalam pengembangannya untuk mencapai sebuah tujuan pembelajaran, yaitu salah satunya menciptakan suasana yang kondusif dan mengembangkan sumber belajar". Di antara bentuk pembelajaran yang disarankan dalam KTSP adalah model pembelajaran kooperatif tipe student teams achievement division (STAD). Student teams achievement division (STAD) merupakan salah satu model dalam pembelajaran kooperatif yang sederhana dan baik untuk guru yang baru mulai menggunakan pendekatan kooperatif dalam kelas (Aqib, 78:2013). Pembelajaran kooperatif tipe student teams achievement division (STAD) ini merupakan salah satu tipe dari 2 model pembelajaran kooperatif dengan menggunakan kelompok-kelompok kecil dengan jumlah anggota kelompok 4-5 orang siswa heterogen. Diawali dengan penyampaian tujuan pembelajaran, penyampaian materi, kegiatan kelompok, kuis, dan penghargaan kelompok (Trianto, 2010). Tujuan penelitian ini adalah untuk mengetahui pengaruh model pembelajaran kooperatif tipe student teams achievement division (STAD) terhadap hasil belajar fisika siswa kelas X SMA Negeri 2 Muara Beliti tahun pelajaran 2015/2016.

\section{B. Landasan Teori}

1. Model Pembelajaran Kooperatif tipe Student Teams Achievement Division (STAD).

Menurut Trianto (2010:52), model pembelajaran kooperatif tipe student teams achievement division (STAD) ini merupakan salah satu tipe dari 2 model pembelajaran kooperatif dengan menggunakan kelompokkelompok kecil dengan jumlah anggota kelompok 4-5 orang siswa heterogen. Diawali dengan penyampaian tujuan pembelajaran, penyampaian materi, kegiatan kelompok, kuis, dan penghargaan kelompok. Sedangkan menurut Isjoni (2010:74) model pembelajaran kooperatif tipe student teams achievement division (STAD) pembelajaran merupakan salah satu tipe kooperatif yang menekankan pembelajaran pada adanya aktivitas dan 
interaksi diantara siswa untuk saling memotivasi dan saling membantu dalam menguasai materi pelajaran guna mencapai prestasi yang maksimal.

Menurut Trianto (2010:54). langkah-langkah model pembelajaran kooperatif tipe student teams achievement division (STAD) terdiri dari enam fase, yang disajikan pada Tabel 2.1.

Tabel 2.1.

Fase-Fase Model Student Teams Achievement Division (STAD)

\begin{tabular}{|c|c|}
\hline Fase & Guru \\
\hline $\begin{array}{l}\text { Fase } 1 \\
\text { Menyampaikan } \\
\text { tujuan dan } \\
\text { memotivasi siswa }\end{array}$ & $\begin{array}{l}\text { Menyampaikan semua } \\
\text { tujuan pelajaran yang } \\
\text { ingin dicapai pada } \\
\text { pelajaran tersebut dan } \\
\text { memotivasi siswa } \\
\text { belajar. }\end{array}$ \\
\hline $\begin{array}{l}\text { Fase } 2 \\
\text { Menyajikan atau } \\
\text { menyampaikan } \\
\text { informasi }\end{array}$ & $\begin{array}{l}\text { Menyajikan informasi } \\
\text { kepada siswa dengan } \\
\text { jalan } \\
\text { mendemonstrasikan } \\
\text { atau lewat bahan } \\
\text { bacaan. }\end{array}$ \\
\hline $\begin{array}{ll}\text { Fase } 3 & \\
\text { Mengorganisasikan } \\
\text { siswa r dalam } \\
\text { kelompok } & \text { kelompok } \\
\text { belajar } & \end{array}$ & \begin{tabular}{lr}
\multicolumn{2}{l}{ Menjelaskan kepada } \\
siswa bagaimana \\
caranya membentuk \\
kelompok belajar dan \\
membantu setiap \\
kelompok agar \\
melakukan transisi \\
secara efisien
\end{tabular} \\
\hline $\begin{array}{l}\text { Fase } 4 \\
\text { Membimbing } \\
\text { kelompok bekerja } \\
\text { dan belajar }\end{array}$ & $\begin{array}{l}\text { Membimbing } \\
\text { kelompok kelompok } \\
\text { belajar Pada saat } \\
\text { mereka mengerjakan } \\
\text { tugas mereka. }\end{array}$ \\
\hline $\begin{array}{l}\text { Fase } 5 \\
\text { Evaluasi }\end{array}$ & $\begin{array}{l}\text { Mengevaluasi hasil } \\
\text { belajar tentang materi } \\
\text { yang telah diajarkan } \\
\text { atau masing-masing } \\
\text { kelompok } \\
\text { mempresentasikan } \\
\text { hasil kerjanya. }\end{array}$ \\
\hline $\begin{array}{l}\text { Fase } 6 \\
\text { Memberikan } \\
\text { penghargaan }\end{array}$ & $\begin{array}{l}\text { Mencari cara-cara } \\
\text { untuk menghargai } \\
\text { baik upaya maupun } \\
\text { hasil belajar individu } \\
\text { dan kelompok }\end{array}$ \\
\hline
\end{tabular}

(Sumber: Trianto, 2007:54)

Menurut Edi, dkk (2009:109) langkah-langkah model pembelajaran kooperatif tipe student teams achievement division (STAD) sebagai berikut:

1) Guru menyampaikan semua tujuan pembelajaran yang ingin dicapai pada pembelajaran tersebut dan memotivasi siswa belajar.

2) Guru menyajikan informasi kepada siswa baik dengan peragaan atau teks.

3) Guru menjelaskan pada siswa bagaimana caranya membentuk kelompok belajar dan membantu setiap kelompok agar melakukan transisi yang efisien.

4) Guru membimbing kelompok-kelompok belajar pada saat mereka mengerjakan tugas.

5) Guru mengevaluasi hasil belajar tentang materi yang telah dipelajari atau masingmasing kelompok mempresentasikan hasil kerjanya.

6) Guru mencari cara-cara untuk menghargai baik upaya maupun hasil belajar individu dan kelompok.

\section{Hasil Belajar}

Faktor intern dan ekstern atau faktor dari dalam diri siswa maupun dari luar diri siswa itu sangat berpengaruh untuk mencapai hasil belajar siswa yang maksimal. Menurut Jihad dan Haris (2008:14) hasil belajar adalah suatu proses dari seseorang yang berusaha untuk memperoleh suatu bentuk perubahan perilaku yang relatif menetap.

\section{Metode Penelitian}

Sugiyono (2010:14) menyatakan bahwa penelitian kuantitatif adalah penelitian yang berlandaskan pada filsafat positivisme, digunakan untuk meneliti pada populasi dan sampel tertentu, teknik pengambilan sampel pada umumnya dilakukan secara random, pengumpulan data menggunakan instrumen penelitian, analisis data bersifat kuantitatif/statistik dengan tujuan untuk menguji hipotesis yang telah diterapkan. Metode penelitian eksperimen merupakan metode penelitian yang digunakan untuk mencari pengaruh treatmeant (perlakuan) tertentu (Sugiyono, 2010:11). Pada penelitian ini menggunakan desain berbentuk pretestposttest control group design atau desain kelompok kontrol eksperimen. Populasi dalam penelitian ini adalah seluruh siswa kelas $X$ di SMA Negeri 2 Muara Beliti tahun pelajaran 2015/2016, yang terdiri dari 8 kelas dan berjumlah 216 siswa. Dalam penelitian ini sampel yang diambil yaitu dua kelas secara acak dengan teknik simple random sampling. Sampel yang diambil yaitu dua kelas yang diambil secara acak (simple random sampling). Tes yang digunakan dalam penelitian ini berbentuk uraian sebanyak 5 soal, peneliti melakukan tes untuk mengetahui hasil belajar. Untuk mengetahui hasil penelitian merupakan hipotesis diterima atau ditolak maka data diuji 
dengan menggunakan t-tes. Dalam menggunakan t-tes ini kedua data baik kelas eksperimen maupun kelas kontrol harus normal dan mempunyai varians yang homogen, oleh karena itu terlebih dahulu mencari nilai rata-rata dan varians dari masingmasing kelompok data, kemudian melakukan uji normalitas dan uji homogenitas.

\section{Hasil Penelitian}

1. Deskripsi Data Analisis dari Hasil Pre-test Pemberian pre-test digunakan untuk mengetahui kemampuan awal siswa pada materi pengukuran dan masing-masing individu sebelum mengikuti proses belajar mengajar. Kemampuan awal adalah kemampuan yang dimiliki siswa sebelum mengikuti pembelajaran yang diberikan. Hasil pre-test tersebut menggambarkan kesiapan siswa dalam menerima pembelajaran yang akan disampaikan oleh guru.

a. Rata-rata $\left(x^{-}\right)$dan simpangan baku (s)

Rekapitulasi rata-rata dan simpangan baku dari pre-tes dapat dilihat pada tabel 4.1

Tabel 4.1

Nilai Rata-Rata dan Simpangan Baku Hasil Tes Awal

\begin{tabular}{|c|c|c|c|}
\hline Kelas & $\mathbf{N}$ & $\boldsymbol{x}^{-}$ & $\mathbf{S}$ \\
\hline Eksperimen & 28 & 14,36 & 6,33 \\
\hline Kontrol & 28 & 15,36 & 7,19 \\
\hline
\end{tabular}

b. Uji Normalitas

Uji normalitas bertujuan untuk melihat apakah data hasil tes siswa berdistribusi normal atau tidak.

Tabel 4.2

Hasil Uji Normalitas Nilai Tes Awal

\begin{tabular}{|c|c|c|c|c|}
\hline Kelas & $\begin{array}{c}\chi 2 \text { hit } \\
\text { ung }\end{array}$ & DK & $\begin{array}{c}\chi 2 \text { ta } \\
\text { bel }\end{array}$ & $\begin{array}{c}\text { Kesim } \\
\text { pulan }\end{array}$ \\
\hline $\begin{array}{c}\text { Eksperi } \\
\text { men }\end{array}$ & 7,17 & 5 & 11,07 & Normal \\
\hline Kontrol & 7,08 & 5 & 11,07 & Normal \\
\hline
\end{tabular}

c. Uji Homogenitas

Berdasarkan ketentuan perhitungan statistika, tentang uji homogenitas varians dengan taraf kepercayaan $\alpha=$ 0,05, jika Fhitung < Ftabel maka varians dua kelompok data adalah homogen.

Tabel 4.3

Hasil Uji Homogenitas Nilai Tes Awal

\begin{tabular}{|c|c|c|c|c|}
\hline Tes & $\begin{array}{c}\text { Fhit } \\
\text { ung }\end{array}$ & DK & $\begin{array}{c}\text { Ftab } \\
\text { el }\end{array}$ & Kesimpulan \\
\hline Tes & 1,29 & $(27:$ & 1,88 & Homogen \\
Awal & & $27)$ & & \\
\hline
\end{tabular}

\section{d. Uji Kesamaan Dua Rata-Rata}

Berdasarkan hasil uji normalitas dan homogenitas, maka kedua kelompok tes awal adalah normal dan homogen. Dengan demikian uji hipotesis antara kelas eksperimen dan kelas kontrol dapat menggunakan uji-t.

Tabel 4.4

Uji Hipotesis Nilai Tes Awal

\begin{tabular}{|c|c|c|c|c|}
\hline Data & thitung & $\begin{array}{c}\text { D } \\
\text { K }\end{array}$ & $\begin{array}{c}\text { ttab } \\
\text { el }\end{array}$ & Kesimpulan \\
\hline Tes & $-0,53$ & 60 & 2,00 & $\begin{array}{l}\text { t hitung }<\text { ttabel } \\
\text { H0 diterima }\end{array}$ \\
Awal & & & & \\
\hline
\end{tabular}

Untuk melihat hasil dari pre-test pada kelas eksperimen dan kelas kontrol dapat dilihat pada gambar di bawah ini:

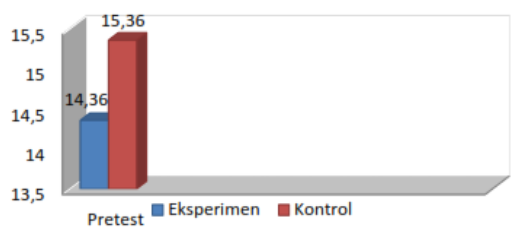

Gambar 4.3 nilai rata-rata Pre-test

2. Deskripsi Data Analisis dari Hasil PostTest

a. Rata-rata $\left(x^{-}\right)$dan simpangan baku (s)

Rekapitulasi rata-rata dan simpangan baku dari post-test dapat dilihat pada tabel 4.5.

Tabel 4.5

Nilai Rata-Rata dan Simpangan Baku Hasil Tes Akhir

\begin{tabular}{|c|c|c|c|}
\hline Kelas & $\mathbf{N}$ & $\boldsymbol{x}^{-}$ & $\mathbf{S}$ \\
\hline Eksperimen & 28 & 82,36 & 7,01 \\
\hline Kontrol & 28 & 64,43 & 9,22 \\
\hline
\end{tabular}

Peningkatan kelas eksperimen lebih besar dari peningkatan kelas kontrol.

b. Uji normalitas

Hasil uji normalitas tes akhir untuk kedua kelompok dapat dilihat pada tabel 4.6.

Tabel 4.6

Hasil Uji Normalitas Nilai Tes Akhir

\begin{tabular}{|c|c|c|c|c|}
\hline Kelas & $\begin{array}{c}\chi 2 \mathrm{hit} \\
\text { ung }\end{array}$ & $\begin{array}{c}\mathbf{D} \\
\mathbf{K}\end{array}$ & $\begin{array}{c}\chi 2 \text { tabe } \\
\boldsymbol{l}\end{array}$ & $\begin{array}{c}\text { Kesimpu } \\
\text { lan }\end{array}$ \\
\hline $\begin{array}{c}\text { Eksperi } \\
\text { men }\end{array}$ & 9,41 & 5 & 11,07 & Normal \\
\hline Kontrol & 9,41 & 5 & 11,07 & Normal \\
\hline
\end{tabular}

c. Uji homogenitas

Berdasarkan ketentuan statistika tentang uji homogenitas varians dengan taraf kepercayaaan $\alpha=0,05$, jika Fhitung < Ftabel maka varians dua kelompok data adalah homogen. 
Tabel 4.7

Hasil Uji Homogenitas Nilai Tes Akhir

\begin{tabular}{|c|c|c|c|c|}
\hline Tes & $\begin{array}{l}\text { Fhitu } \\
\text { ng }\end{array}$ & DK & $\begin{array}{l}\text { Ftab } \\
\text { el }\end{array}$ & Kesimpulan \\
\hline $\begin{array}{c}\text { Tes } \\
\text { Awal }\end{array}$ & 1,73 & $\begin{array}{l}(27: \\
27)\end{array}$ & 1,88 & Homogen \\
\hline
\end{tabular}

d. Uji kesamaan dua rata-rata

Hasil perhitungan menunjukan bahwa data hasil belajar siswa kelas $X 3$ sebagai kelas eksperimen dan kelas $X 8$ sebagai kelas kontrol berdistribusi normal dan homogen. Dengan demikian uji hipotesis antara kelas eksperimen dan kelas kontrol untuk data tes akhir maupun kontrol menggunakan uji-t .

Tabel 4.8

Uji Hipotesis Nilai Tes Akhir

\begin{tabular}{|l|l|l|l|l|}
\hline Data & thitung & DK & $\begin{array}{l}\text { ttab } \\
\text { el }\end{array}$ & Kesimpulan \\
\hline $\begin{array}{l}\text { Tes } \\
\text { Akhir }\end{array}$ & 7,83 & 60 & 1,67 & $\begin{array}{l}\text { thitung }>\text { t tabel } \\
\text { H0 ditolak }\end{array}$ \\
\hline \multicolumn{4}{|c|}{ Hipotesis statistik yang diuji dalam }
\end{tabular}
perhitungan uji-t untuk tes akhir adalah: H0 : Hipotesis pembanding, nilai rata-rata kelas eksperimen lebih kecil dari pada nilai rata-rata kelas kontrol.

Ha : Hipotesis kerja, nilai rata-rata kelas eksperimen lebih besar dari pada nilai ratarata kelas kontrol. Berdasarkan hasil perhitungan uji-t mengenai kemampuan tes akhir, menunjukkan bahwa thitung $>$ ttabel $(7,83>1,67)$ sehingga Ho ditolak. Untuk melihat hasil dari post-test pada kelas eksperimen dan kelas kontrol dapat dilihat pada gambar 4.6.

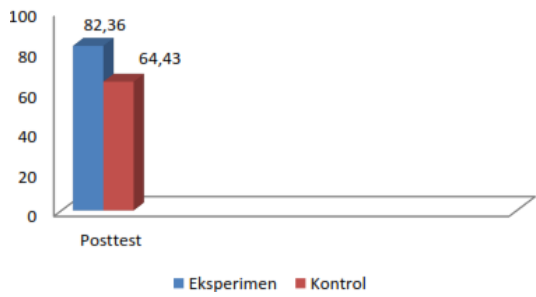

Gambar 4.6 nilai rata-rata post-test

\section{E. Pembahasan}

Permasalahan yang dibahas dalam penelitian ini yaitu apakah ada pengaruh yang signifikan model pembelajaran kooperatif tipe student teams achivement division (STAD) terhadap hasil belajar fisika siswa kelas X pada materi pengukuran. Kemudian kedua kelompok diberi perlakuan yang berbeda, yaitu kelas eksperimen diberi perlakuan dengan menggunakan model pembelajaran kooperatif tipe student teams achivement division (STAD) sedangkan kelas kontrol diberi perlakuan dengan metode ceramah dan tanya jawab.
Pada pertemuan pertama hari kamis tanggal 06 Agustus 2015 dengan jumlah 28 siswa peneliti membagikan soal pretes. Saat pembagian soal pretest siswa sangat bingung karena mereka sudah lupa akan materi pengukuran yang pernah diajarkan di SMP. Kegaduhan di kelas mulai terjadi tapi setelah diberi penjelasan kenapa peneliti memberi soal tersebut akhirnya siswa mengerti juga dan mengerjakan soal semampunya. Pada pertemuan kedua hari kamis tanggal 13 Agustus 2015 dengan jumlah 28 siswa materi pengukuran besaran panjang. Pelaksanaan pembelajaran pada kelas eksperimen dengan model pembelajaran kooperatif tipe student teams achivement division (STAD) mengalami sedikit hambatan. Pembelajaran yang baru bagi siswa, sehingga siswa membutuhkan waktu untuk penyesuaian. Pada saat siswa dibagi dalam beberapa kelompok kegaduhan mulai terjadi dalam kelas, hal ini dikarenakan siswa ingin memilih kelompok sendiri dan keberatan akan kelompok yang sudah dipilihkan serta siswa masih bingung dengan cara kerja alat ukur panjang karena fasilitas alat yang kurang. Pada pertemuan ketiga hari kamis tanggal 20 Agustus 2015 dengan jumlah 28 siswa materi pengukuran massa dan waktu. Pelaksanaan pembelajaran pada kelas eksperimen menggunakan model pembelajaran kooperatif tipe student teams achivement division (STAD) dan kelas kontrol menggunakan metode pembelajaran ceramah dan tanya jawab. Pada kelas eksperimen siswa mulai terbiasa belajar menggunakan model pembelajaran kooperatif tipe student teams achivement division $(S T A D)$, dan siswa sudah mulai bisa bekerja sama dengan anggota kelompok dan saling membagi pengetahuan dengan kelompok lain serta siswa perlahan mulai terbiasa dengan model pembelajaran kooperatif tipe student teams achivement division (STAD. Hambatan yang dirasakan siswa secara perlahan dapat berkurang karena siswa mulai tertarik dengan model pembelajaran kooperatif tipe student teams achivement division (STAD), siswa menjadi lebih kompak dengan kelompoknya dan dapat menjawab LKS yang telah diberikan. Pembelajaran pada kelas eksperimen dengan menggunakan model pembelajaran kooperatif tipe student teams achivement division (STAD), siswa menjadi lebih semangat belajar, siswa menjadi lebih aktif, dan semakin meningkatnya rasa tanggung jawab siswa terhadap diri sendiri maupun terhadap siswa lain. Berbeda dengan pembelajaran yang dilaksanakan pada kelas kontrol, pembelajaran yang menggunakan 
metode ceramah dan tanya jawab. Pada saat guru menjelaskan materi pelajaran siswa banyak bercerita dengan teman sebangkunya, tidak memperhatikan penjelasan guru. Hanya siswa tertentu yang memperhatikan guru saat menjelaskan materi. Kegiatan ini lebih berpusat pada guru, sehingga siswa menjadi pasif dan tidak aktif dalam belajar. Pada saat guru menanyakan siapa yang belum paham, siswa hanya diam sehingga membuat guru kurang mengetahui batas pemahaman siswa. Berdasarkan analisis data posttest maka terjadi peningkatan hasil belajar. Terdapat perbedaan hasil belajar antara kelas eksperimen dan kelas kontrol. Hal ini disebabkan oleh perbedaan perlakuan yang diberikan pada kelas eksperimen dan kelas kontrol. Kelas eksperimen diajarkan dengan menggunakan model pembelajaran kooperatif tipe student teams achivement division (STAD) diperoleh nilai rata-rata 82,36 dibandingkan dengan nilai rata-rata tes awal sebesar 14,36, maka terjadi peningkatan sebesar 68,00 dengan jumlah sebanyak 28 siswa yang nilainya tuntas atau mencapai KKM. Sementara itu, kelas kontrol dengan menggunakan metode ceramah dan tanya jawab diperoleh nilai rata-rata 64,43 dibandingkan dengan nilai rata-rata tes awal sebesar 15,36, maka terjadi peningkatan 49,07 dengan jumlah sebanyak 28 siswa yang nilainya tuntas atau mencapai KKM. Hal ini menunjukkan bahwa rata-rata hasil posttest kelas eksperimen lebih tinggi dibandingkan dengan kelas kontrol. Pada kelas kontrol menggunakan metode pembelajaran ceramah dan tanya jawab, siswa hanya duduk dan memperhatikan guru yang menjelaskan materi pelajaran. Keadaan seperti ini mengakibatkan siswa yang belum jelas atau kurang paham tidak berani atau malu bertanya pada guru. Sedangkan saat guru bertanya siswa cenderung diam. Pada saat mengerjakan soal latihan sebagian siswa saja yang serius mengerjakan soal yang diberikan oleh guru sedangkan selebihnya bermain-main bersama temannya. Selain itu, guru juga harus memperhatikan faktor intern dan ekstern dari siswa. Hasil belajar siswa yang tidak tuntas juga dapat disebabkan oleh kebiasaan belajar yang dilakukan oleh siswa di rumah, kemampuan yang dimiliki siswa rendah, kurang bekerja sama dengan temannya, dan kurangnya motivasi untuk belajar. Sehingga guru harus memberikan perhatian yang lebih daripada siswa yang lain.

\section{F. Kesimpulan}

Berdasarkan hasil penelitian dan pembahasan, dapat disimpulkan bahwa ada pengaruh yang signifikan model pembelajaran kooperatif tipe student teams achivement division (STAD) terhadap hasil belajar fisika siswa kelas $\mathrm{X}$ SMA Negeri 2 Muara Beliti tahun pelajaran 2015/2016.

\section{DAFTAR PUSTAKA}

Abdurrahman, Mulyono. 2012. Anak Kesulitan Belajar: Teori, Diagnosis, dan Remediasinya. Jakarta: PT Rineka Cipta.

Aqib, Zainal. 2013. Model-model media dan strategi pembelajaran konsektual

inovatif. Bandung: Yrama widya.

Arikunto, Suharsimi. 2010. Prosedur Penelitian Suatu Pendekatan Praktik.

Jakarta: Rineka Cipta.

Edi, dkk. 2009. Penerapan Pembelajaran Kooperatif Tipe STAD Berorientasi

Keterampilan Proses. Jurnal Pendidikan Fisika Indonesia, 5, 108-112.

Hamalik, Oemar. 2010. Proses Belajar Mengajar. Bandung: Bumi Aksara.

Hatika, dkk. 2014. Pengaruh Model Pembelajaran Kooperatif Tipe Student Teams Achievement Division (STAD) Terhadap Hasil Belajar Kognitif Fisika

Siswa SMK N 1 Rambah Tahun Pembelajaran 2014/2015. Pillar Of

Physics Education, 1, 1-6.

Isjoni. (2010). Pembelajaran Kooperatif meningkatkan Kecerdasan Komunikasi

Antar Peserta Didik. Yogyakarta : Pustaka Pelajar.

Jihad, Asep, dan Haris, Abdul. 2008. Evaluasi

Pembelajaran. Yogyakarta: Multi

Slameto. 2010. Belajar dan Faktor-faktor yang Mempengaruhi. Jakarta: Rineka

Cipta.

Sudjana. 2005. Metode Statistika. Bandung: Tarsito.

Sudijono, Anas. 1998. Pengantar Evaluasi Pendidikan. Jakarta : PT. Raja

Grafindo Persada.

Sugiyono.2011.Metode Penelitian Pendidikan Pendekatan Kuantitatif Kualitatatif

dan R\&D. Bandung: Alfabeta.

Trianto. 2010. Mendesain Model Pembelajaran Inovatif-Progresif: Konsep Landasan dan Implementasinya pada Kurikulum Tingkat Satuan Pendidikan (KTSP). Jakarta: Kencana Prenada Media Group. 